\title{
Significance of Low Density Lipoprotein Production in the Regulation of Plasma Cholesterol Level in Man
}

\author{
Y. Antero Kesaniemi and Scott M. Grundy, Veterans Administration Medical \\ Center, University of California, San Diego, California 92161
}

A B S TRACT To determine whether production or catabolism of low density lipoprotein (LDL) is the major factor controlling LDL concentrations in subjects with plasma cholesterol levels from low-normal to mildly elevated, measurements of apoprotein of LDL (apoLDL) turnover were performed in 16 patients with various plasma cholesterol concentrations. Cholesterol balance studies were done simultaneously in 13 of these patients. Plasma concentrations of apoLDL and LDL-cholesterol were positively correlated with synthetic rates of apoLDL $(r=0.74, P$ $<0.001 ; r=0.50, P<0.05$, respectively). No correlation was noted between the fractional catabolic rate for apoLDL and apoLDL levels (or LDL-cholesterol). For further analysis, the patients were divided into three groups with stepwise increases in apoLDL concentrations. When apoLDL levels rose significantly, from $83 \pm 5$ SEM to $122 \pm 2$ to $149 \pm 5 \mathrm{mg} / \mathrm{dl}$, synthetic rates for apoLDL also increased significantly from $11.6 \pm 1.2$ to $17.0 \pm 0.9$ to $23.8 \pm 1.8 \mathrm{mg} / \mathrm{d} / \mathrm{kg}$ ideal weight. In contrast, the fractional catabolic rate of apoLDL was not different among the three groups $(0.32 \pm 0.03$ vs. $0.29 \pm 0.02$ vs. $0.33 \pm 0.03 / d)$. No relation was noted between synthesis of total body cholesterol (or bile acids) and concentrations, production rates, or removal of apoLDL. Thus, concentrations of apoLDL and LDL-cholesterol in these subjects with plasma cholesterol levels from low-normal to mildly elevated were regulated mainly by synthetic rates of apoLDL and not by LDL catabolism.

\section{INTRODUCTION}

Plasma cholesterol concentrations in the general population are correlated highly with levels of cholesterol in low density lipoproteins (LDL). ${ }^{1}$ The concentrations

Received for publication 28 September 1981 and in revised form 25 February 1982.

${ }^{1}$ Abbreviations used in this paper: apoLDL, apoprotein of LDL; CHD, coronary heart disease; FCR, fractional catabolic rate; FH, familial hypercholesterolemia; HDL, high density lipoprotein; LDL, low density lipoprotein; VLDL, very low density lipoprotein. of the latter should be a function of both synthesis and clearance of LDL. Studies (1-3) have demonstrated that clearance of LDL may be mediated in part by specific receptors for LDL on the surface of cells. The importance of LDL receptors in regulating LDL concentrations is illustrated by the genetic disorder, familial hypercholesterolemia, which is characterized by a deficiency of receptors and marked elevations in LDL levels. Beyond this disorder, however, little is known about control of LDL concentrations in patients with other primary forms of hypercholesterolemia.

Furthermore, there is a wide range in total plasma and LDL-cholesterol in the United States population, but factors determining this variability are poorly understood. One possibility is that LDL levels over the "normal" range may be controlled primarily through the metabolism of apolipoprotein B, the almost exclusive apoprotein of LDL (apoLDL). For this reason, we have examined synthetic and clearance rates of apoLDL and their role in regulating LDL concentrations in a group of subjects showing a broad range in levels from low-normal to mildly elevated. The major purpose of the study was to determine whether production or clearance of LDL is the major factor controlling LDL concentrations. Our results indicate that synthetic rates of apoLDL, and not clearance rates, are the predominant factor determining plasma apoLDL and LDL-cholesterol in subjects of this category.

\section{METHODS}

Patients. 16 patients with various levels of plasma cholesterol from low-normal to mild hypercholesterolemia were admitted into the Special Diagnostic and Treatment Unit (metabolic unit) of the Veterans Administration Medical Center, San Diego, CA. The sex, age, and body habitus at time of metabolic studies, and diagnosis of each patient are presented in Table I. Two of the patients had a history of a well documented myocardial infarction. Routine clinical laboratory tests indicated that all the individuals were free of diabetes mellitus, thyroid disease, hepatic disease, and renal dysfunction. Detailed family studies according to Goldstein et al. $(4,5)$ were not done. None of the patients appeared to have familial hypercholesterolemia because of 
TABLE I

Clinical Data

\begin{tabular}{rccccc}
\hline Patient & Sex & Age & Weight & $\begin{array}{c}\text { Ideal } \\
\text { weight }\end{array}$ & $\begin{array}{c}\text { Clinical } \\
\text { diagnosis }\end{array}$ \\
\hline & $F / M$ & $y r$ & $k g$ & $\%$ & \\
1 & $M$ & 62 & 75.2 & 114 & Normal \\
2 & $\mathrm{M}$ & 54 & 74.6 & 101 & Normal \\
3 & $\mathrm{M}$ & 68 & 55.9 & 81 & Normal \\
4 & $\mathrm{M}$ & 56 & 78.4 & 110 & Normal \\
5 & $\mathrm{M}$ & 62 & 92.2 & 118 & Normal \\
6 & $\mathrm{M}$ & 58 & 66.6 & 114 & Normal \\
7 & $\mathrm{M}$ & 47 & 78.8 & 113 & Normal \\
8 & $\mathrm{~F}$ & 59 & 74.7 & 127 & Normal \\
9 & $\mathrm{M}$ & 61 & 87.1 & 122 & Normal \\
10 & $\mathrm{M}$ & 67 & 74.8 & 108 & CHD \\
11 & $\mathrm{M}$ & 63 & 89.3 & 114 & Normal \\
12 & $\mathrm{M}$ & 60 & 60.1 & 82 & Normal \\
13 & $\mathrm{M}$ & 57 & 74.3 & 113 & CHD \\
14 & $\mathrm{M}$ & 31 & 71.5 & 100 & Normal \\
15 & $\mathrm{~F}$ & 59 & 70.6 & 138 & Normal \\
16 & $\mathrm{M}$ & 54 & 124.6 & 189 & Normal \\
\hline
\end{tabular}

- CHD, coronary heart disease.

the lack of marked hypercholesterolemia, tendon xanthomas, or history of unusually premature coronary disease; also family histories of these abnormalities were absent. None of the patients had been on a cholesterol-lowering diet or drug therapy before the study. All patients gave informed consent for the investigation.

Diets. The patients were fed a diet of mixed solid food and liquid formula containing $40 \%$ of calories as fat. The basic composition and pattern of this diet has been described in detail (6). Three liquid meals and one solid-food meal were given per day. Calories were divided approximately equally between feedings. The liquid meals were given at 8:30 a.m., 1:00 p.m., and 7:00 p.m. They contained 15\% of calories as milk protein, $45 \%$ as dextrose, and $40 \%$ as fat mostly as lard. This liquid formula was prepared by Hospital Diet Products, Organon Inc., Buena Park, CA (courtesy of Mr. Fred Teixeira). One solid-food meal was given at 11:00 a.m., and it contained dry cereal (corn flakes), nonfat bread, skim milk, added fat, and sugar for coffee. Fat comprised $\sim \mathbf{4 0 \%}$ calories in solid-food meals. Cholesterol intakes are listed in Table V. The ratio of polyunsaturated-to-saturated fats was 0.2 . Vitamin and mineral supplements were given daily. Each patient was weighed daily, and caloric intake was adjusted to maintain total body weight at a constant level throughout the study period.

Lipoprotein turnover studies. After the patients had been on the mixed solid food and liquid formula diet described above for $10 \mathrm{~d}$ to $2 \mathrm{wk}$, plasmapheresis was carried out by collecting blood $(500 \mathrm{ml})$ in sterile, pyrogen-free plastic bags containing $500 \mathrm{mg}$ of the disodium salt of EDTA. After centrifugation $\left(4^{\circ} \mathrm{C}\right)$ at $5,500 \mathrm{~g}$ for $5 \mathrm{~min}$, plasma was separated from cells; the cells were reinfused. Isolation of LDL $(d=1.025-1.060 \mathrm{~g} / \mathrm{ml})$ was carried out according to the method of Lindgren et al. (7). The plasma was adjusted to a density of $1.025 \mathrm{~g} / \mathrm{ml}$ with a sterile solution of $\mathrm{NaCl}$ $\mathrm{NaBr}$ and centrifuged in a 60Ti rotor in a $\mathrm{L2}-65 \mathrm{~B}$ preparative ultracentrifuge (Beckman Instruments, Inc., Spinco
Div., Palo Alto, CA) at $60,000 \mathrm{rpm}\left(15^{\circ} \mathrm{C}\right)$ for $18 \mathrm{~h}$. The infranate was adjusted to a density of $1.060 \mathrm{~g} / \mathrm{ml}$ by the addition of $\mathrm{NaCl}-\mathrm{NaBr}$ and subjected to further ultracentrifugation for $14 \mathrm{~h}$ in a 65 rotor at $65,000 \mathrm{rpm}\left(15^{\circ} \mathrm{C}\right)$. A final ultracentrifugation was done in a 40.3 rotor at 39,000 $\mathrm{rpm}$ for $24 \mathrm{~h}\left(15^{\circ} \mathrm{C}\right)$ after overlaying with an equal volume of a NaCl- $\mathrm{NaBr}$ solution of density $1.070 \mathrm{~g} / \mathrm{ml}$. The concentrated LDL was then dialyzed against $0.15 \mathrm{M} \mathrm{NaCl}$ containing 0.01\% EDTA (pH 7.4).

The apoprotein of LDL was labeled with ${ }^{125}$ I by the iodine monochloride method of McFarlane (8) as modified by Bilheimer et al. (9). Reactants were added in a way as to assure a ratio of iodine atoms to moles of protein of $<1$. The efficiency of radiolabeling of LDL actually achieved was 7.2$27.1 \%$, with an average of $16.9 \%$.

The degree of lipid labeling was determined by extraction of the labeled LDL with a chloroform/methanol solvent $(2: 1$, $\mathrm{vol} / \mathrm{vol}$ ) using the method of Folch et al. (10). The organic phase was evaporated to dryness, and residual lipid was counted in dry tubes. The mean percentage of counts in the lipid moiety was $3.7 \%$ (range 0.97 to $7.0 \%$ ).

The mean amount of unbound iodine after dialysis was checked by thin-layer chromatography on Gelman ITLC-SG sheets (Gelman Sciences, Inc., Ann Arbor, MI) using 20\% trichloroacetic acid containing $0.125 \%$ sodium metabisulfite as a chromatography system. The number of counts at the solvent front compared with the total counts present was taken to represent the percentage of ${ }^{125} \mathrm{I}$ not bound to LDL protein. This amount averaged $0.33 \%$ (range 0.13 to $0.95 \%$ ).

After removal of unbound ${ }^{125} \mathrm{I}$ by dialysis, the ${ }^{125} \mathrm{I}$-LDL preparation was subjected to centrifugation at $20,000 \mathrm{~g}$ for $30 \mathrm{~min}\left(4^{\circ} \mathrm{C}\right)$, the supernatant removed and passed through a 0.22-micron Millipore filter (Millipore Corp., Bedford, MA). Sterile human serum albumin in a $5 \%$ solution was added to the ${ }^{125} \mathrm{I}-\mathrm{LDL}$ to dilute the final product to a concentration of $10 \mu \mathrm{Ci} / \mathrm{ml}$. This solution was then passed again through a 0.22 -micron Millipore filter and aliquots were set aside for bacterial and fungal culture and for pyrogen testing.

$5 \mathrm{~d}$ after plasmapheresis, $\sim 2-10 \mathrm{mg}$ of ${ }^{125} \mathrm{I}-\mathrm{LDL}$ protein (17-70 $\mu \mathrm{Ci})$ was injected intravenously. Blood samples $(7 \mathrm{ml})$ were collected at $5,10,15,20,30$, and $60 \mathrm{~min}$ and $3,6,9$, $12,24,36$, and $48 \mathrm{~h}$, and daily (fasting) thereafter for 14$21 \mathrm{~d}$. Determinations of radioactivity and total cholesterol and triglyceride concentrations were made on each sample. Lipoprotein quantification was done biweekly during the study period. Urine specimens were collected in bottles containing an alkaline preservative (11) and were pooled during the following time intervals after the intravenous injection of ${ }^{125}$ I-LDL: " 0 time" to $1,1-3,3-6,6-12$, and $12-24 \mathrm{~h}$, and for every 24-h period thereafter. Values for urinary radioactivity were normalized to a constant creatinine excretion. All radioactivity was determined in a Packard model 5820 automatic gamma scintillation spectrometer (Packard Instrument Co., Inc., Downers Grove, IL). The patients received 0.5-0.9 $\mathrm{g}$ of $\mathrm{KI}$ orally in divided doses each day to suppress ${ }^{125}$ I uptake by the thyroid.

The kinetic parameters for LDL turnover were calculated using methods originally described by Matthews (12) and by Nosslin (13) and later adapted to LDL turnover studies by Langer et al. (14). Two exponential components were fit to the plasma die-away data using standard curve-peeling methods. The calculated curve gave results for the percentage of the apoLDL pool in the intravascular space and the fractional catabolic rate (FCR) (defined as the fraction of the intravascular pool of LDL catabolized per day). Plasma volume was calculated by the isotope dilution technique 
from the known injected dose and the intercept of the calculated two-exponential curve. The FCR was measured independently by relating the daily urinary excretion rate of ${ }^{125} \mathrm{I}$ radioactivity to the ${ }^{125} \mathrm{I}$ radioactivity in plasma $(\mathrm{U} / \mathrm{P}$ ratio) (15). U/P radioactivity ratios were calculated using the mean plasma radioactivity values of each 24 -h period. The rate of synthesis for apoLDL was calculated using the following formula and was expressed as milligrams of apoLDL synthesized per day (14):SR $=(\mathrm{FCR}) \times(\mathrm{PV})$ $X$ (apoLDL concentration), where $S R=$ rate of synthesis, $\mathrm{FCR}=$ fractional catabolic rate , and $\mathrm{PV}=$ plasma volume The concentration of apoLDL was calculated from the mean of the 4-6 measured values for LDL-cholesterol and the 46 measured ratios of protein-to-cholesterol in each patient's LDL. These measurements were done twice weekly throughout the study. LDL-protein was determined by the method of Lowry et al. (16).

Because patients of this study were of different heights and weights it was necessary to normalize the results so that the results in one individual could be compared meaningfully to another. A common method for normalizing synthetic rates for apoLDL is to express them as milligrams per day per kilogram total body weight. However, as recently shown by Grundy et al. (17), calculations of transport rates per kilogram total body weight may be misleading. In obese subjects, it can reduce calculated synthetic rates to inordinately low values, as compared with absolute rates. In other words, dividing synthesis rates by a large mass of adipose tissue could obscure real increases in production of apoLDL. a process presumably confined to the liver and plasma compartment. To overcome this problem, Grundy et al. (17) proposed that synthetic rates be expressed as milligrams per kilogram ideal weight. Their work showed a high correlation between synthesis rates of VLDL-triglycerides expressed this way and absolute synthetic rates for subjects of all degrees of obesity. For this reason, synthesis rates of apoLDL will be expressed preferentially as milligrams per day per kilo- gram ideal weight. Ideal weight was calculated from life insurance tables (18). As will be indicated in Results, normalization to total body weight does not produce substantially different results for most patients.

Plasma lipids and lipoproteins. Blood was obtained twice weekly after a 12-h fast for plasma lipids and lipoprotein quantification. Total plasma cholesterol and triglycerides were determined on a Technicon Auto-Analyzer [model 11 Technicon Instruments Corp., Tarrytown, NY $(19,20)]$. Concentrations of cholesterol and triglycerides in very low density lipoproteins (VLDL), LDL, and high density lipoproteins (HDL) were estimated as described in the Lipid Research Clinics Manual of Laboratory Operations (21).

Cholesterol balance studies. Estimations of cholesterol balance were made as described earlier (22-25). Stools were collected throughout the study period and usually combined into 7 -d pools. Fecal neutral and acidic steroids were isolated separately, and their masses were determined by gas-liquid chromatography $(22,23)$. Gas-liquid chromatography analysis of neutral steroids distinguished between cholesterol and plant sterols and their steroid conversion products. Analyses were carried out entirely by chemical procedures. To correct for losses of neutral steroids, beta-sitosterol was given as capsules (225 mg twice daily) (24), and excretions of acidic steroids were corrected for variations in fecal flow by use of chromic oxide (25)

\section{RESULTS}

Plasma lipids and lipoproteins. Values for cholesterol and triglyceride in total plasma and each lipoprotein fraction are shown in Table II. Total cholesterol ranged from 162 to $322 \mathrm{mg} / \mathrm{dl}$. Four patients had plasma cholesterol levels above the 95 th percentile for the corresponding age and sex group according to the

TABLE II

Plasma Lipids and Lipoproteins

\begin{tabular}{ccccccccc}
\hline & No. & Total & & VLD & VLDL & LDL & LDL & HDL \\
chatient & Total TG & cholesterol & TG & cholesterol & TG & cholesterol & TG \\
\hline
\end{tabular}

$m g / d l \pm S E M$

\begin{tabular}{|c|c|c|c|c|c|c|c|c|c|}
\hline 1 & 7 & $201 \pm 3$ & $109 \pm 6$ & $15 \pm 1$ & $65 \pm 5$ & $130 \pm 4$ & $21 \pm 2$ & $56 \pm 1$ & $23 \pm 1$ \\
\hline 2 & 8 & $162 \pm 3$ & $149 \pm 8$ & $28 \pm 5$ & $91 \pm 9$ & $104 \pm 10$ & $23 \pm 3$ & $45 \pm 4$ & $31 \pm 4$ \\
\hline 3 & 8 & $221 \pm 4$ & $78 \pm 3$ & $11 \pm 1$ & $42 \pm 2$ & $128 \pm 4$ & $13 \pm 2$ & $82 \pm 1$ & $22 \pm 2$ \\
\hline 4 & 9 & $252 \pm 6$ & $244 \pm 15$ & $41 \pm 2$ & $194 \pm 16$ & $160 \pm 6$ & $31 \pm 2$ & $51 \pm 3$ & $18 \pm 2$ \\
\hline 5 & 6 & $284 \pm 13$ & $194 \pm 13$ & $36 \pm 3$ & $139 \pm 11$ & $197 \pm 11$ & $31 \pm 2$ & $52 \pm 3$ & $25 \pm 3$ \\
\hline 6 & 9 & $230 \pm 7$ & $188 \pm 12$ & $34 \pm 3$ & $133 \pm 11$ & $149 \pm 4$ & $25 \pm 2$ & $47 \pm 2$ & $30 \pm 3$ \\
\hline 7 & 9 & $233 \pm 5$ & $151 \pm 9$ & $25 \pm 2$ & $101 \pm 8$ & $155 \pm 7$ & $28 \pm 1$ & $53 \pm 3$ & $23 \pm 1$ \\
\hline 8 & 10 & $270 \pm 4$ & $116 \pm 8$ & $16 \pm 2$ & $57 \pm 6$ & $184 \pm 4$ & $33 \pm 2$ & $70 \pm 1$ & $26 \pm 1$ \\
\hline 9 & 9 & $239 \pm 3$ & $149 \pm 5$ & $24 \pm 2$ & $99 \pm 5$ & $170 \pm 3$ & $24 \pm 1$ & $45 \pm 1$ & $26 \pm 1$ \\
\hline 10 & 4 & $246 \pm 5$ & $210 \pm 8$ & $49 \pm 6$ & $154 \pm 8$ & $160 \pm 9$ & $35 \pm 3$ & $37 \pm 2$ & $21 \pm 3$ \\
\hline 11 & 10 & $285 \pm 5^{\circ}$ & $210 \pm 12$ & $40 \pm 3$ & $152 \pm 10$ & $192 \pm 5$ & $26 \pm 1$ & $52 \pm 1$ & $31 \pm 2$ \\
\hline 12 & 13 & $267 \pm 5$ & $193 \pm 7$ & $35 \pm 2$ & $136 \pm 7$ & $194 \pm 4$ & $29 \pm 2$ & $38 \pm 1$ & $28 \pm 1$ \\
\hline 13 & 10 & $322 \pm 5^{\circ}$ & $167 \pm 5$ & $29 \pm 1$ & $115 \pm 5$ & $231 \pm 5^{\circ}$ & $26 \pm 1$ & $61 \pm 2$ & $27 \pm 1$ \\
\hline 14 & 9 & $260 \pm 6^{\circ}$ & $241 \pm 11$ & $50 \pm 4$ & $175 \pm 9$ & $177 \pm 7$ & $36 \pm 3$ & $34 \pm 3$ & $31 \pm 2$ \\
\hline 15 & 7 & $309 \pm 10^{\circ}$ & $207 \pm 11$ & $36 \pm 4$ & $130 \pm 11$ & $218 \pm 8^{\circ}$ & $49 \pm 4$ & $55 \pm 3$ & $28 \pm 3$ \\
\hline 16 & 6 & $269 \pm 4$ & $214 \pm 10$ & $42 \pm 3$ & $158 \pm 9$ & $191 \pm 6$ & $34 \pm 2$ & $36 \pm 2$ & $23 \pm 3$ \\
\hline
\end{tabular}

- The measurement above 95 percentile value of the corresponding age and sex group $(23,24)$. 
TABLE III

Kinetic Parameters for ${ }^{125}$ I-apoLDL Turnover

\begin{tabular}{|c|c|c|c|c|c|c|c|c|}
\hline \multirow{3}{*}{ Patient } & \multirow{3}{*}{$\begin{array}{c}\begin{array}{c}\text { Plasma } \\
\text { volume }\end{array} \\
\mathrm{ml}\end{array}$} & \multirow{3}{*}{$\begin{array}{c}\begin{array}{c}\text { Plasma } \\
\text { apoLDL }\end{array} \\
\mathrm{mg} / \mathrm{dl}\end{array}$} & \multirow{3}{*}{$\begin{array}{l}\text { LDL protein/ } \\
\text { cholesterol ratio }\end{array}$} & \multicolumn{2}{|c|}{ FCR ${ }^{\bullet}$} & & & \multirow{2}{*}{$\begin{array}{c}\text { Intravascullart } \\
\text { apoLDL }\end{array}$} \\
\hline & & & & Group 1 & Group 2 & \multicolumn{2}{|c|}{ Rate of synthesis of apoLDL } & \\
\hline & & & & \multicolumn{2}{|c|}{ per day } & $\mathrm{mg} / \mathrm{day} / \mathrm{kg}$ & $m g / d a y / k g l W$ & $\%$ \\
\hline 1 & 3,671 & 92 & 0.71 & 0.289 & 0.264 & 13.0 & 14.9 & 80.2 \\
\hline 2 & 3,225 & 76 & 0.73 & 0.324 & 0.390 & 10.6 & 10.7 & 72.9 \\
\hline 3 & 2,612 & 74 & 0.58 & 0.403 & 0.410 & 13.9 & 11.3 & 66.8 \\
\hline 4 & 2,908 & 90 & 0.56 & 0.259 & 0.259 & 8.6 & 9.5 & 76.9 \\
\hline 5 & 3,807 & 118 & 0.60 & 0.264 & 0.298 & 12.9 & 15.2 & 81.1 \\
\hline 6 & 3,148 & 128 & 0.86 & 0.295 & 0.264 & 17.9 & 20.4 & 81.4 \\
\hline 7 & 3,427 & 121 & 0.78 & 0.306 & 0.294 & 16.1 & 18.2 & 79.6 \\
\hline 8 & 2,820 & 128 & 0.70 & 0.236 & 0.241 & 11.4 & 14.5 & 76.8 \\
\hline 9 & 3,667 & 124 & 0.73 & 0.250 & 0.289 & 13.1 & 15.9 & 77.0 \\
\hline 10 & 2,782 & 115 & 0.72 & 0.378 & 0.426 & 16.3 & 17.6 & 83.4 \\
\hline 11 & 4,136 & 154 & 0.80 & 0.330 & - & 23.5 & 26.7 & 75.8 \\
\hline 12 & 3,193 & 167 & 0.86 & 0.298 & 0.230 & 26.4 & 21.6 & 78.0 \\
\hline 13 & 2,835 & 157 & 0.68 & 0.260 & 0.205 & 15.6 & 17.6 & 76.4 \\
\hline 14 & 3,067 & 142 & 0.80 & 0.441 & 0.445 & 26.9 & 26.9 & 78.5 \\
\hline 15 & 2,644 & 140 & 0.64 & 0.291 & 0.298 & 15.3 & 21.0 & 80.4 \\
\hline 16 & 3,822 & 132 & 0.69 & 0.382 & 0.418 & 15.2 & 29.2 & 84.8 \\
\hline
\end{tabular}

- Fraction of intravascular apoLDL pool metabolized each day, calculated either from the two exponentials of the plasma die-away curve (1) or from $U / P$ ratio (2).

† Percentage of total body apoLDL contained in the intravascular space.

Lipid Research Clinics Program Prevalence Study (26, 27). The plasma triglyceride values ranged from 78 to $244 \mathrm{mg} / \mathrm{dl}$, and all the values fell below the 95th percentile $(26,27)$. LDL-cholesterol varied from 104 to $231 \mathrm{mg} / \mathrm{dl}$, and in two patients values exceeded the 95th percentile for the general population. HDL-cholesterol ranged from 34 to $82 \mathrm{mg} / \mathrm{dl}$.

ApoLDL kinetics. Table III shows kinetic parameters for ${ }^{125} \mathrm{I}$-apoLDL in each of the 16 patients. ApoLDL concentrations ranged from 74 to $167 \mathrm{mg}$ / dl. The FCR for apoLDL as calculated from the plasma radioactivity die-away curve ranged from 0.236 to $0.441 / \mathrm{d}$. Similar results were obtained when FCR was calculated from U/P ratios. No significant correlation could be found between plasma apoLDL concentrations and FCR $(r=0.10)$. In contrasts, synthetic rates varied from 9.5 to $29.2 \mathrm{mg} / \mathrm{d} / \mathrm{kg}$ ideal weight and were correlated positively with plasma apoLDL concentrations $(r=0.74 ; P<0.001)$ (Fig. 1). If synthetic rates were expressed as milligrams per day per kilogram the correlation was still significant $(r$ $=0.70, P<0.01)$. A high correlation between plasma apoLDL levels and synthetic rates also was found among the 12 subjects whose total cholesterol concentrations fell below the 95th percentile for age and sex $(r=0.74, P<0.01)$.

Significant correlations were observed between synthetic rates of apoLDL and (a) LDL-cholesterol $(r$
$=0.05, P<0.05)($ Fig. 2), (b) LDL-protein/cholesterol ratios $(r=0.55, P<0.05)$ (Fig. 3) and (c) plasma total triglycerides $(r=0.52, P<0.05)$. Almost significant were the relations between apoLDL synthesis and $(d)$ plasma total cholesterol $(r=0.45, P<0.08)$, $(e)$ VLDLtriglycerides $(r=0.47, P<0.06)$, and $(f)$ total body weight $(r=0.43, P<0.10)$. None of these six parameters were correlated significantly with FCR of apoLDL $(r=-0.25,-0.28,0.28,-0.20,0.19$, and 0.01 , respectively).

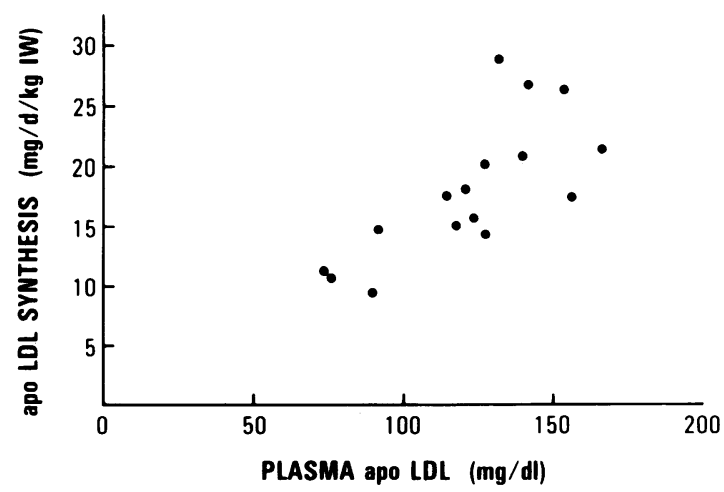

Figure 1 The relation between the apoLDL synthetic rates and the plasma apoLDL concentrations in patients with various plasma cholesterol levels. Individual values are listed in Table III. $r=0.74 ; P<0.001$. 


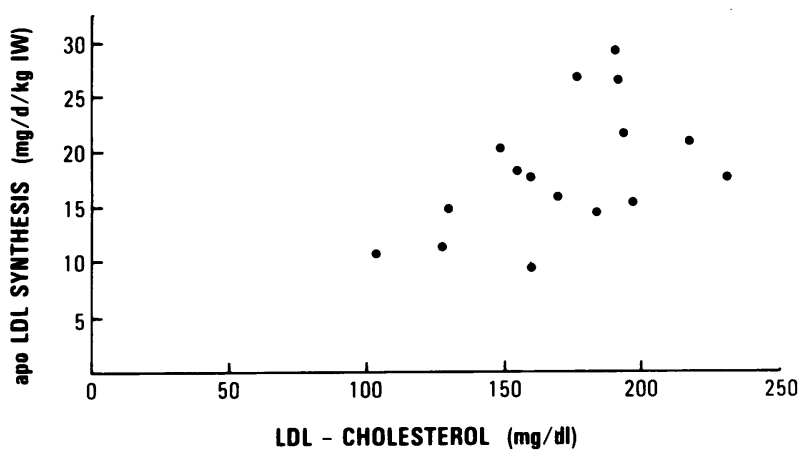

Figure 2 The relation between the apoLDL synthetic rates and the plasma LDL-cholesterol concentrations in patients with various plasma cholesterol levels. Individual values are listed in Tables II and III. $r=0.5 ; P<0.05$.

The relations between concentrations and synthesis of apoLDL were examined in another way in Table IV. The patients were divided into three groups according to their apoLDL concentrations: group 1 (apoLDL $<100 \mathrm{mg} / \mathrm{dl})$, group $2($ apoLDL $=100-130$ $\mathrm{mg} / \mathrm{dl}$ ), and group 3 (apoLDL $<130 \mathrm{mg} / \mathrm{dl}$ ). In these groups, mean levels of apoLDL increased significantly from 83 to 122 to $149 \mathrm{mg} / \mathrm{dl}$; LDL-cholesterol rose significantly from 131 to 169 to $201 \mathrm{mg} / \mathrm{dl}$; and synthetic rates for apoLDL increased significantly from 11.6 to 17.0 to $23.8 \mathrm{mg} / \mathrm{d}$ per $\mathrm{kg}$ ideal weight. In contrast, the FCR of apoLDL remained unchanged $(0.319$, 0.288 , and 0.334 , respectively).

Cholesterol balance. Measurements of cholesterol balance were carried out in 13 patients (Table V). The

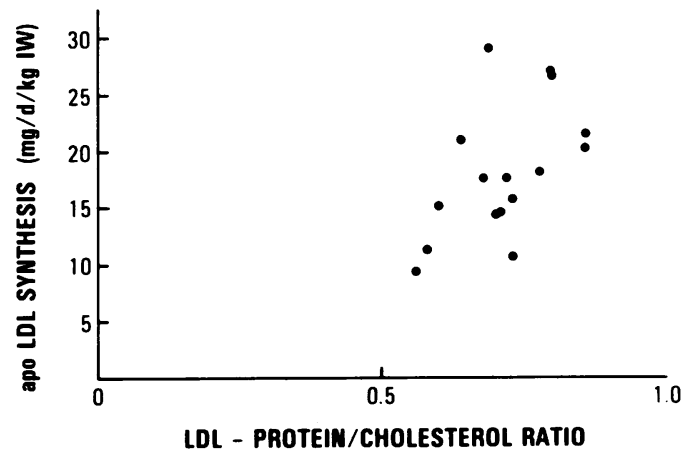

Figure 3 The relation between the apoLDL synthetic rates and LDL-protein/cholesterol ratios in patients with various plasma cholesterol levels. Individual values are listed in $\mathrm{Ta}$ ble III. $r=0.55 ; P<0.05$.

patients were also subdivided into the three groups described above. Although patients in group 1 had numerically higher values for synthesis of cholesterol and bile acids, the difference between this group and the others was not statistically significant. Synthesis rates of neither cholesterol nor bile acids were correlated with apoLDL synthesis $(r=-0.14,0.16$, respectively) or FCR of apoLDL $(r=-0.20,-0.19$, respectively).

\section{DISCUSSION}

In this study subjects with plasma cholesterol concentrations from low-normal to mildly elevated were examined to evaluate the role of apoLDL synthesis and

TABLE IV

Clinical Data, Plasma Lipids, and Kinetic Parameters for ${ }^{125}$ I-apoLDL Turnover Studies as Subgrouped According to the Plasma apoLDL Concentration ${ }^{\circ}$

\begin{tabular}{|c|c|c|c|c|c|c|c|c|c|c|c|}
\hline \multirow{3}{*}{$\begin{array}{c}\text { Group } \\
\text { (patient) }\end{array}$} & \multirow{3}{*}{$\begin{array}{c}\begin{array}{c}\text { Body } \\
\text { weight }\end{array} \\
k g\end{array}$} & \multirow{3}{*}{$\frac{\text { IBW }}{\%}$} & \multirow{3}{*}{$\begin{array}{c}\text { Total } \\
\text { cholesterol }\end{array}$} & \multirow{3}{*}{ Total TG } & \multirow{3}{*}{$\begin{array}{c}\begin{array}{c}\text { LDL } \\
\text { cholesterol }\end{array} \\
\mathrm{mg} / \mathrm{dl}\end{array}$} & \multirow{3}{*}{$\begin{array}{c}\text { HDL } \\
\text { cholesterol }\end{array}$} & \multirow{3}{*}{$\begin{array}{l}\text { Plasma } \\
\text { apoLDL }\end{array}$} & \multicolumn{2}{|c|}{ FCR $\mathbf{t}$} & \multirow{2}{*}{\multicolumn{2}{|c|}{ Rate of synthesis of apoLDL }} \\
\hline & & & & & & & & 1 & 2 & & \\
\hline & & & & & & & & & day & $m g / d / k g$ & $m g / d / k g I W$ \\
\hline $\begin{array}{c}1 \\
(1-4)\end{array}$ & $71 \pm 5$ & $102 \pm 7$ & $209 \pm 19$ & $145 \pm 36$ & $131 \pm 12$ & $59 \pm 8$ & $83 \pm 5$ & $0.319 \pm 0.031$ & $0.331 \pm 0.040$ & $11.5 \pm 1.2$ & $11.6 \pm 1.2$ \\
\hline $\begin{array}{c}2 \\
(5-10)\end{array}$ & $79 \pm 4$ & $117 \pm 3$ & $250 \pm 9$ & $168 \pm 14$ & $169 \pm 4 \S$ & $51 \pm 5$ & $122 \pm 2 \S$ & $0.288 \pm 0.021$ & $0.302 \pm 0.026$ & $14.6 \pm 1.0$ & $17.0 \pm 0.9 \S$ \\
\hline $\begin{array}{c}3 \\
(11-16)\end{array}$ & $82 \pm 9$ & $123 \pm 15$ & $285 \pm 10^{1 / \pi}$ & $205 \pm 10$ & $201 \pm 8^{\| \pi}$ & $46 \pm 5$ & $149 \pm 5^{\| \pi}$ & $0.334 \pm 0.027$ & $0.319 \pm 0.048^{\circ}$ & $20.5 \pm 2.3^{\| \pi}$ & $23.8 \pm 1.8^{\| \pi}$ \\
\hline
\end{tabular}

- The data subgrouped from Tables I, II, and III, (mean \pm SEM).

$\downarrow$ Fraction of intravascular apoLDL pool metabolized each day, calculated either from the two exponentials of the plasma die-away curve (1) or from $U / P$ ratio (2).

$\$ 2$ significantly higher than 1 ( $P<0.02$ or less).

" 3 significantly higher than 1 ( $P<0.01$ or less).

I 3 significantly higher than $2(P<0.05$ or less $)$.

$\cdots$ Average of only five values. 
TABLE V

Cholesterol Balance Data

\begin{tabular}{|c|c|c|c|c|c|c|c|c|c|}
\hline \multirow[b]{3}{*}{ Patient } & \multirow{3}{*}{$\begin{array}{c}\text { Dietary } \\
\text { cholesterol } \\
\text { intake (a) }\end{array}$} & \multicolumn{3}{|c|}{ Fecal steroid excretion } & \multirow{3}{*}{$\begin{array}{c}\text { Steroid } \\
\text { balance } \\
(\mathbf{b}-\mathbf{a})\end{array}$} & \multirow{2}{*}{\multicolumn{4}{|c|}{ Synthetic rate ${ }^{\bullet}$}} \\
\hline & & \multirow{3}{*}{ Neutral } & \multirow{3}{*}{$\frac{\text { Acidic }}{m g / d}$} & \multirow{3}{*}{$\begin{array}{l}\text { Total } \\
\text { (b) }\end{array}$} & & & & & \\
\hline & & & & & & \multicolumn{2}{|c|}{ Cholesterol } & \multicolumn{2}{|c|}{ Bile acids } \\
\hline & $m g / d$ & & & & $m g / d$ & $m g / k g / d$ & $m g / k g I W / d$ & $m g / k g / d$ & $\mathrm{mg} / \mathrm{kgIW} / \mathrm{d}$ \\
\hline 1 & 120 & 1232 & 678 & 1,910 & 1,790 & 23.8 & 27.1 & 9.0 & 10.3 \\
\hline 2 & 104 & 858 & 455 & 1,312 & 1,208 & 16.2 & 16.3 & 6.1 & 6.2 \\
\hline 3 & 129 & 525 & 400 & 924 & 795 & 14.2 & 11.5 & 7.2 & 5.8 \\
\hline 4 & 112 & 692 & 856 & 1,547 & 1,435 & 18.3 & 20.1 & 10.9 & 12.0 \\
\hline 5 & 121 & 592 & 474 & 1,066 & 945 & 10.2 & 12.1 & 5.1 & 6.1 \\
\hline 6 & 98 & 346 & 277 & 623 & 525 & 7.9 & 9.0 & 4.2 & 4.7 \\
\hline 7 & 86 & 724 & 564 & 1,288 & 1,202 & 15.3 & 17.2 & 7.2 & 8.1 \\
\hline 9 & 112 & 560 & 736 & 1,296 & 1,184 & 13.6 & 16.6 & 8.5 & 10.3 \\
\hline 11 & 120 & 943 & 724 & 1,667 & 1,547 & 17.3 & 19.8 & 8.1 & 9.2 \\
\hline 13 & 99 & 633 & 563 & 1,196 & 1,097 & 14.8 & 16.7 & 7.6 & 8.6 \\
\hline 14 & 122 & 441 & 441 & 882 & 760 & 10.6 & 10.6 & 6.2 & 6.2 \\
\hline 15 & 91 & 267 & 339 & 606 & 515 & 7.3 & 10.1 & 4.8 & 6.6 \\
\hline 16 & 151 & 454 & 904 & 1,357 & 1,206 & 9.7 & 18.3 & 7.3 & 13.7 \\
\hline Group $1 \rrbracket$ & & & & & & 18.1 & 18.8 & 8.3 & 8.6 \\
\hline$(1-4)$ & & & & & & \pm 2.1 & \pm 3.3 & \pm 1.1 & \pm 1.5 \\
\hline Group 2 & & & & & & 11.8 & 13.7 & 6.3 & 7.3 \\
\hline$(5,6,7,9)$ & & & & & & \pm 1.7 & \pm 1.9 & \pm 1.0 & \pm 1.2 \\
\hline Group 3 & & & & & & 11.9 & 15.1 & 6.8 & 8.9 \\
\hline$(11,13-16)$ & & & & & & \pm 1.8 & \pm 2.0 & \pm 0.6 & \pm 1.3 \\
\hline
\end{tabular}

- The synthetic rate of total cholesterol was determined by dividing the total steroid balance (b-a) by the body weight (Table I). The synthetic rate of bile acids was determined by dividing the bile acid excretion (acidic fecal steroid excretion) by the body weight. The values for total cholesterol synthesis include values for both neutral sterols and bile acids.

$\$$ The data subgrouped according to the plasma apoLDL concentration as in Table IV

catabolism in regulation of plasma apoLDL and LDLcholesterol levels. The major finding was that concentrations of apoLDL and LDL-cholesterol over a broad range of LDL levels were regulated mainly by synthetic rates of apoLDL. However, as will be discussed below, production rates were not the only factor determining concentrations of apoLDL and LDL-cholesterol, even though they appeared to be the dominant influence.

Our findings in subjects whose LDL-cholesterol varied over the normal range differ from those in patients with familial hypercholesterolemia (FH) in that their fractional clearance rates did not decrease with increasing LDL levels. Several studies $(14,28-33)$ have shown that FH patients have decreased clearance of LDL, which is consistent with their deficiency of LDL receptors. Values for FCR of apoLDL in patients with heterozygous $\mathrm{FH}$ range between 0.15 and $0.25 / \mathrm{d}(14$, $32-35)$. An exception to these relatively low FCR in FH was reported by Bilheimer et al. (31); these workers noted higher values with a mean of $0.287 / \mathrm{d}$. Also, in their study (31), normal subjects had a higher mean FCR $(0.450 / d)$ than that reported for normal in most other studies $(14,32-35)$, that is, $\sim 0.35 / \mathrm{d}$ (from 0.30 to $0.40 / \mathrm{d}$ ). Of note, both control subjects and FH patients of Bilheimer et al. (31) were younger and had higher ratios of dietary polyunsaturated fats-to-saturated fats $(\mathrm{P} / \mathrm{S}$ ratio) than those of most other studies including the present one. It is possible that young adults with low LDL will show higher FCR than older subjects with somewhat higher concentrations of LDL; also Shepherd et al. (36) have reported that a high P/ $\mathrm{S}$ ratio increases the FCR. Thus, the range of 0.15 to $0.25 / \mathrm{d}$ in FCR for FH patients would seem appropriate for comparison with present results.

Our current subjects had FCR for apoLDL ranging from 0.236 to $0.441 / \mathrm{d}$ with a mean of $0.313 \pm 0.015$ (SEM)/d. Although several patients with differing levels of LDL-cholesterol had an FCR below $0.30 / \mathrm{d}$, there was no clinical evidence that any of the patients had FH. Their total and LDL-cholesterol were not markedly elevated to levels usually found in FH patients; 
they did not have tendon xanthoma nor a family history of such lesions; their family histories were devoid of unusually premature coronary heart disease. Indeed only two patients had distinctly elevated LDL-cholesterol, and in these, levels were only slightly increased. Thus, in our patients without FH, no correlation was observed between FCR and levels of apoLDL over a wide range of concentrations; furthermore, there was no trend for decreasing FCR with rising LDL concentrations as if the clearance system was "saturated."

The most notable feature of the patients of this study was a broad range of synthetic rates of apoLDL that correlated closely with apoLDL concentrations. These rates varied from 9.5 to $29.5 \mathrm{mg} / \mathrm{d}$ per $\mathrm{kg}$ ideal weight ( 8.6 to $26.9 \mathrm{mg} / \mathrm{d}$ per $\mathrm{kg}$ ) in patients whose LDL-cholesterol levels ranged from 104 to $231 \mathrm{mg} / \mathrm{dl}$. It is interesting to compare these production rates to those reported previously for normocholesterolemic subjects by other workers. Fig. 4 plots concentrations against synthesis of apoLDL for previous studies (31-34, 36-

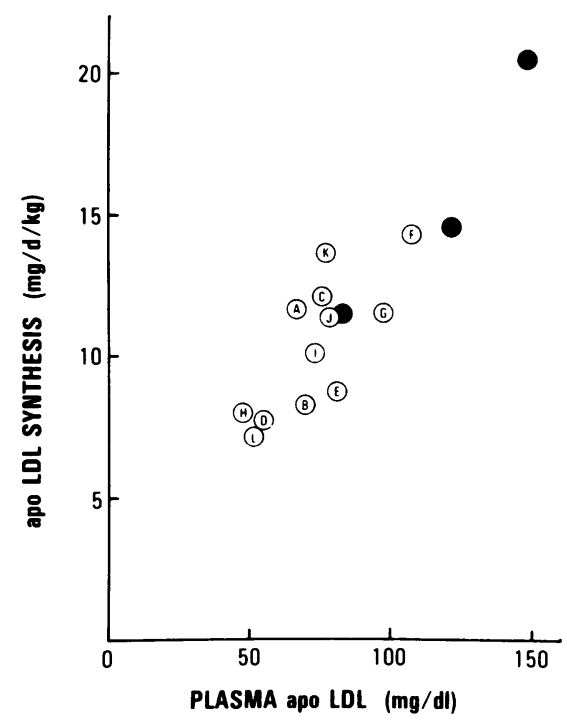

Figure 4 The relation between the apoLDL synthetic rates and the plasma apoLDL concentrations in normolipidemic individuals reported in the literature (open circles) $\mathrm{A}=\mathrm{Sig}$ urdsson et al. (34), B = Reardon et al. (37), C = Nestel et al. (38), $\mathrm{D}=$ Janus et al. (32), $\mathrm{E}=$ Packard et al. (39), $\mathrm{F}$ = Walton et al. (40), $\mathrm{G}=$ Packard et al. (33), $\mathrm{H}=$ Bilheimer et al. (30), I = Calvert et al. (41), J = Shepherd et al. (36), $\mathrm{K}$ and $\mathrm{L}=$ Garnick et al. (42), $\mathrm{K}=$ white Americans, $\mathrm{L}$ $=$ American Indians. Some of the values were derived or approximated from the published results. The density range of LDL varied among these studies (1.006-1.063 vs. 1.0191.063). In addition, the values for the patients with various plasma cholesterol levels of the present study are given as subgrouped in Table IV (solid circles).
42) as related to the present study. Although types of subjects, diets, and other conditions varied to some extent among the different reports, the comparisons are of interest nevertheless. As shown by Fig. 4, results of our study for low apoLDL levels fit well with previous findings. Most previous studies have been done in subjects in the low-normal range of apoLDL and LDL-cholesterol. Even in this range, however, there appears to be a fairly good correlation between apoLDL levels and production rates. Unfortunately, few studies have been done in subjects in the highnormal range for comparison, but as shown by the present work, correlations noted at lower concentrations appear to extend to higher ones as well.

The synthetic rates of apoLDL of the present study were expressed as milligrams per day per kilogram ideal weight. Theoretically, it might have been better to normalize to lean body mass, but this parameter was not determined for the current patients. Nevertheless, these patients were not obese (mean percent ideal body weight $=115 \% \pm 6 \mathrm{SEM}$ ) and the differences in apoLDL synthetic rates were essentially the same whether expressed as milligrams per day per kilogram ideal weight or milligrams per day per kilogram.

As indicated above, it is unlikely that any of our patients had FH. However, it is possible that those whose total cholesterol exceeded the 95th percentile may have had another familial hyperlipidemia, such as familial combined hyperlipidemia or polygenic hypercholesterolemia $(5,43)$. Patients with familial combined hyperlipidemia have been reported to have overproduction of VLDL-apoprotein B $(32,44)$, which could lead to increased synthesis of apoLDL; these patients presumably do not have a reduced FCR for apoLDL. However, it should be emphasized that a positive correlation between concentrations and synthesis of apoLDL also was observed in the group of patients whose LDL-cholesterol (and total cholesterol) were below the 95 th percentile. This again supports the concept that the concentration of LDL-cholesterol in the range from low to high normal is determined mainly by synthetic rates.

An important question concerns the source of LDL in subjects of this study. Two possibilities must be considered. First, LDL might be derived from the catabolism of VLDL; and second, it could be the product of direct synthesis. Phillips et al. (45) have reported a positive correlation between VLDL-triglycerides and LDL-cholesterol in subjects with total triglycerides over the normal range. Their observation suggests that increasing production rates of VLDL may be associated with a rise in concentrations of LDL. In our study, apoLDL synthesis was significantly related to plasma total triglycerides $(r=0.52, P<0.05)$ and almost sig- 
nificantly to VLDL-triglycerides $(r=0.47, P<0.06)$; this observation also suggests that VLDL concentrations (and perhaps VLDL synthesis rates) partially regulate LDL concentrations.

Several previous reports indicate that subjects with normal concentrations of LDL derive almost all of their LDL from VLDL $(9,34,37,46-48)$. In patients with FH, however, a significant portion of LDL appears to arise by direct secretion (VLDL-independent synthesis of LDL) $(35,49)$. Indeed patients with both homozygous and heterozygous forms of $\mathrm{FH}$ have higher than normal synthetic rates of apoLDL (2931 ), and most of their excess synthesis may occur via direct secretion of LDL. The reasons for an enhanced production of LDL in FH are not understood but may be related to defective regulation of LDL production secondary to decreased hepatic receptors for LDL (31). Whether subjects with LDL levels in the high normal range have direct secretion of LDL has not been determined.

What might be the basis for the variability of synthetic rates of apoLDL in the general population? One factor could be diet. People on diets rich in saturated fats and cholesterol, which raise LDL-cholesterol concentrations, also may have a high production of apoLDL. This possibility finds support in the recent report of Nestel et al. (50) that reduced concentrations of plasma LDL in vegetarians are explained mainly by low production rates of LDL apoprotein $B$. The effects of diet composition could not be evaluated in the current study because all the patients were on the same diet. Therefore, factors other than differences in dietary fat and cholesterol must have contributed to their variability in synthetic rates. Another factor affecting apoLDL production in the general population could be adiposity (or total caloric intake). In our study apoLDL synthesis in milligrams per day was not correlated with either total caloric intake $(r=0.34)$ or percent ideal body weight $(r=0.27)$, but since we did not specifically study obese patients, such patients still may have overproduction of apoLDL. Thus we are left with the conclusion that differences in apoLDL synthesis in our patients, under the current experimental design, probably were genetic in origin; this suggests that genetic differences in apoLDL synthesis may influence LDL concentrations in the general population. Nonetheless, in our view, more studies are needed on the role of diet composition and caloric intake in regulating synthesis of apoLDL.

Although the present data indicate that synthesis rates of apoLDL strongly influence apoLDL concentrations over the normal range, it should be pointed out that these rates are not the only factor controlling cholesterol concentrations in LDL. While the rela- tionship between synthetic rates of apoLDL and levels of LDL-cholesterol was statistically significant, the correlation coefficient was only 0.50 (Fig. 2); therefore other influences must have been involved. One additional factor affecting both apoLDL and LDL-cholesterol in individual patients was the FCR. For the whole group, FCR ranged from 0.236 to $0.441 / \mathrm{d}$, and each individual's FCR obviously influenced his LDL concentration. Furthermore, it should be noted that catabolism of LDL is complex in that removal can occur by either receptor-mediated or receptor-independent pathways (1-3, 51-53); also LDL receptors can be located on both hepatic and extrahepatic cells. Little is known about the relative role of these different pathways in man, and their magnitude could vary from person to person. Thus, the patients of this study may have had genetic variability in the control of their FCR, as in their synthetic rates, and future studies may reveal subgroups in whom the FCR uniformly influences LDL concentrations.

Another factor affecting LDL-cholesterol was the LDL-protein/cholesterol ratio. This ratio varied from 0.58 to 0.86 in our 16 patients. Factors controlling the protein/cholesterol ratio in LDL have not been determined, but in this study, a significant correlation was found between this ratio and apoLDL synthesis. This finding may shed some light on the recent work of Sniderman et al. (54). These workers claim that LDL-apoB concentrations segregate patients with coronary heart disease (CHD) from individuals without CHD better than do plasma total cholesterol, triglycerides, or LDL-cholesterol. They specifically observed a group of CHD patients who had normal LDL-cholesterol but increased LDL-apoB; these patients obviously had a high apoB/cholesterol ratio in LDL. We did not specifically estimate LDL-apoB in the current study, but measured values for plasma apoLDL should be a close approximation of LDL-apoB concentrations. Our finding of a positive correlation between apoLDL synthesis and LDL-protein/cholesterol ratios suggests that patients with high apoLDL synthesis could have disproportionately high apoLDL levels compared with LDL-cholesterol. In other words, a high LDL-protein/cholesterol ratio probably can be explained in part by a high synthetic rate of apoLDL and may be responsible for the hyperapobetalipoproteinemia (with normal LDL-cholesterol) reported by Sniderman et al. (54).

Several studies of cholesterol balance have revealed no differences in total cholesterol synthesis between normal subjects and patients with heterozygous $\mathbf{F H}$ $(31,55,56)$. The present data also revealed no relation between synthesis of either cholesterol or bile acids and concentrations of apoLDL or LDL-cholesterol. 
Furthermore, synthetic rates of these sterols were not related to production or FCR of apoLDL. Thus, the current results are in accord with previous reports indicating a relative independence between metabolism of total body cholesterol and that of LDL.

\section{ACKNOWLEDGMENTS}

The authors wish to express their appreciation to Marjorie Whelan and others of the Nursing and Dietetic Services of the Veterans Administration Medical Center, San Diego, CA, and to Elizabeth Baker, Karen Clark, Janna Naylor, and Susan Butler for their excellent technical assistance.

This work was supported by the Veterans Administration and grant 14197 awarded by National Heart, Lung, and Blood Institute/National Institutes of Health/HDS/Department of Health and Human Services. Dr. Kesaniemi is a visiting scientist from the 2nd Department of Medicine, University of Helsinki, Finland. His research was supported partly by the Merrell Dow Pharmaceuticals Inc., Indianapolis, IN. Dr. Grundy was a Medical Investigator for the Veterans Administration.

\section{REFERENCES}

1. Goldstein, J. L., and M. S. Brown. 1977. The low density lipoprotein pathway and its relation to atherosclerosis. Annu. Rev. Biochem. 46: 897-930.

2. Goldstein, J. L., and M. S. Brown. 1974. Binding and degradation of low density lipoproteins by cultured human fibroblast: comparison of cells from a normal subject and from a patient with homozygous familial hypercholesterolemia. J. Biol. Chem. 249: 5153-5162.

3. Ho, Y. K., J. R. Faust, D. W. Bilheimer, M. S. Brown, and J. L. Goldstein. 1977. Regulation of cholesterol synthesis by low density lipoprotein in isolated human lymphocytes. J. Exp. Med. 145: 1531-1549.

4. Goldstein, J. L., W. R. Hazzard, H. G. Schrott, E. L. Bierman, and A. G. Motulsky. 1973. Hyperlipidemia in coronary heart disease. I. Lipid levels in 500 survivors of myocardial infarction. J. Clin. Invest. 52: 1533-1543.

5. Goldstein, J. L., H. G. Schrott, W. R. Hazzard, E. L. Bierman, and A. G. Motulsky. 1973. Hyperlipidemia in coronary heart disease. II. Genetic analysis of lipid levels in 176 families and delineation of a new inherited disorder, combined hyperlipidemia. J. Clin. Invest. 52: 1544-1568.

6. Grundy, S. M. 1975. Effects of polyunsaturated fats on lipid metabolism in patients with hypertriglyceridemia. J. Clin. Invest. 55: 269-282.

7. Lindgren, F. T., L. C. Jensen, R. D. Wills, and N. K. Freeman. 1969. Flotation rates, molecular weights and hydrated densities of low-density lipoproteins. Lipids. 4: 337-344.

8. McFarlane, A. S. 1958. Efficient trace-labelling of proteins with iodine. Nature (Lond.). 182:53.

9. Bilheimer, D. W., S. Eisenberg, and R. I. Levy. 1972. The metabolism of very low density lipoprotein proteins. I. Preliminary in vitro and in vivo observations. Biochim. Biophys. Acta. 260: 212-221.

10. Folch, J., M. Lees, and G. H. SloaneStanley. 1957. A simple method for the isolation and purification of total lipids from animal tissues. J. Biol Chem. 226: 497-509.

11. Steinfeld, J. L., R. R. Paton, A. L. Flick, R. A. Milch, F. E. Beach, and D. L. Tabern. 1957. Distribution and degradation of human serum albumin labeled with $I^{131}$ by different techniques. Ann. N. Y. Acad. Sci. 70: 109121.

12. Matthews, C. M. E. 1957. The theory of tracer experiments with iodine ${ }^{131}$-labeled plasma proteins. Phys. Med. Biol. 2: 36-53.

13. Nosslin, B. 1964. In Metabolism of Human Gamma Globulin. S. B. Anderson, editor. Scientific Publications, Ltd., Oxford, England. 103-120.

14. Langer, T., W. Strober, and R. I. Levy. 1972. The metabolism of low density lipoprotein in familial type II hyperlipoproteinemia. J. Clin. Invest. 51: 1528-1536.

15. Berson, S. A., and R. S. Yalow. 1957. Distribution and metabolism of $\mathrm{I}^{131}$ labeled proteins in man. Fed. Proc. 16: 13S-18S.

16. Lowry, O. H., N. J. Rosebrough, A. L. Farr, and R. J. Randall. 1951. Protein measurement with the Folin phenol reagent. J. Biol. Chem. 193: 265-275.

17. Grundy, S. M., H. Y. I. Mok, L. Zech, D. Steinberg, and M. Berman. 1979. Transport of very low density lipoprotein triglycerides in varying degrees of obesity and hypertriglyceridemia. J. Clin. Invest. 63: 1274-1283.

18. Metropolitan Life Insurance Company Statistical Bulletin. 1959. November, December. 40.

19. Block, W. D., K. J. Jarrett, and J. B. Levine. 1965. Use of a single color reagent to improve the automated determination of serum total cholesterol. In Automation in analytical chemistry. Mediad Inc., New York 345347.

20. Kessler, G., and H. Lederer. 1965. Fluorometric measurements of triglycerides. In Automation in analytical chemistry. Mediad Inc., New York 341-344.

21. Lipid Research Clinics Program Manual of Laboratory Operations. 1974. Department of Health, Education and Welfare Publication, National Institutes of Health. 75628.

22. Grundy, S. M., E. H. Ahrens, Jr., and T. A. Miettinen. 1965. Quantitative isolation and gas-liquid chromatographic analysis of total fecal bile acids. J. Lipid Res. 6: $397-410$.

23. Miettinen, T. A., E. H. Ahrens, Jr., and S. M. Grundy. 1965. Quantitative isolation and gas-liquid chromatographic analysis of total dietary and fecal neutral steroids. J. Lipid Res. 6: 411-424.

24. Grundy, S. M., E. H. Ahrens, Jr., and G. Salen. 1968. Dietary betasitosterol as an internal standard to correct for cholesterol losses in sterol balance studies. J. Lipid Res. 9: 374-387.

25. Davignon, J., W. J. Simmons, and E. H. Ahrens, Jr. 1968. Usefulness of chromic oxide as an internal standard for balance studies in formula-fed patients and for assessment of colonic function. J. Clin. Invest. 47: 127-138.

26. The Lipid Research Clinics Program Epidemiology Committee. 1979. Plasma lipid distributions in selected North American populations: the Lipid Research Clinics Program Prevalence Study. Circulation. 60: 427-439.

27. Heiss, G., I. Tamir, C. E. Davis, H. A. Tyroler, B. Rifkind, G. Schoenfeld, D. Jacobs, and I. D. Frantz, Jr. 1980. Lipoprotein-cholesterol distributions in selected North American populations: The Lipid Research Clinics Program Prevalence Study. Circulation. 61: 302-315.

28. Reichl, D., L. A. Simons, and N. B. Myant. 1974. The metabolism of low-density lipoprotein in a patient with familial hyperbetalipoproteinaemia. Clin. Sci. Mol. Med. 47: 635-638

29. Simons, L. A., D. Reichl, N. B. Myant, and M. Mancini. 1975. The metabolism of the apoprotein of plasma low 
density lipoprotein in familial hyperbetalipoproteinaemia in the homozygous form. Atherosclerosis. 21: 283298.

30. Bilheimer, D. W., J. L. Goldstein, S. M. Grundy, and M. S. Brown. 1975. Reduction in cholesterol and low density lipoprotein synthesis after portocaval shunt surgery in a patient with homozygous familial hypercholesterolemia. J. Clin. Invest. 56: 1420-1430.

31. Bilheimer, D. W., N. J. Stone, and S. M. Grundy. 1979 Metabolic studies in familial hypercholesterolemia. Evidence for a gene-dosage effect in vivo. J. Clin. Invest. 64: 524-533.

32. Janus, E. D., A. M. Nicoll, P. R. Turner, P. Magill, and B. Lewis. 1980. Kinetic bases of the primary hyperlipidaemias: studies of apolipoprotein B turnover in genetically defined subjects. Eur. J. Clin. Invest. 10: 161172 .

33. Packard, C. J., J. L. H. C. Third, J. Shephard, A. R Lorimer, H. G. Morgan, and T. D. V. Lawrie. 1976. Low density lipoprotein metabolism in a family of familial hypercholesterolemic patients. Metab. Clin. Exp. 25: 995-1006.

34. Sigurdsson, G., A. Nicoll, and B. Lewis. 1975. Conversion of very low density lipoprotein to low density lipoprotein. A metabolic study of apolipoprotein B kinetics in human subjects. J. Clin. Invest. 56: 1481-1490.

35. Soutar, A. K., N. B. Myant, and G. R. Thompson. 1977. Simultaneous measurement of apolipoprotein B turnover in very low- and low-density lipoproteins in familial hypercholesterolemia. Atherosclerosis. 28: 247-256.

36. Shepherd, J., C. J. Packard, S. M. Grundy, D. Yeshurun, A. M. Gotto, Jr., and O. D. Taunton. 1980. Effects of saturated and polyunsaturated fat diets on the chemical composition and metabolism of low density lipoproteins in man. J. Lipid Res. 21: 91-99.

37. Reardon, M. F., N. H. Fidge, and P. J. Nestel. 1978. Catabolism of very low density lipoprotein B apoprotein in man. J. Clin. Invest. 61: 850-860.

38. Nestel, P. J., M. Reardon, and N. H. Fidge. 1979. Sucrose-induced changes in VLDL- and LDL-B apoprotein removal rates. Metab. Clin. Exp. 28: 531-535.

39. Packard, C. J., J. Shepherd, S. Joerns, A. M. Gotto, and O. D. Taunton. 1980. Apolipoprotein B metabolism in normal, type IV and type V hyperlipoproteinemic subjects. Metab. Clin. Exp. 29: 213-221

40. Walton, K. W., P. J. Scott, P. N. Dykes, and J. W. L. Davies. 1965. The significance of alterations in serum lipids in thyroid dysfunction. II. Alterations of the metabolism and turnover of ${ }^{131} \mathrm{I}$-low-density lipoproteins in hypothyroidism and thyrotoxicosis. Clin. Sci. (Lond.). 29: 217-238.

41. Calvert, G. D., and H. M. James. 1979. Low-density lipoprotein turnover studies in man. Evaluation of the integrated rate equations method, use of a whole-body radioactivity counter, and the problem of partial denaturation. Clin. Sci. 56: 71-76.

42. Garnick, M. B., P. H. Bennett, and T. Langer. 1979. Low density lipoprotein metabolism and lipoprotein cholesterol content in southwestern American Indians. J. Lipid Res. 20: 31-39.
43. Goldstein, J. L., H. G. Schrott, W. R. Hazzard, E. L. Bierman, and A. G. Motulsky. 1973. Hyperlipidemia in coronary heart disease. J. Clin. Invest. 52: 1544-1568.

44. Chait, A., J. J. Albers, and J. D. Brunzell. 1980. Very low density lipoprotein overproduction in genetic forms of hypertriglyceridaemia. Eur. J. Clin. Invest. 10: 1722.

45. Phillips, N. R., R. J. Havel, and J. P. Kane. 1981. Levels and interrelationships of serum and lipoprotein cholesterol and triglycerides. Association with adiposity and the consumption of ethanol, tobacco, and beverages containing caffeine. Arteriosclerosis. 1: 13-24.

46. Gitlin, D., D. G. Cornwell, D. Nakasato, J. L. Oncley, W. L. Hughes, and C. A. Janeway. 1958. Studies on the metabolism of plasma protein in the nephrotic syndrome. II. The lipoproteins. J. Clin. Invest. 37: 172-184.

47. Eisenberg, S., D. W. Bilheimer, R. I. Levy, and F. T. Lindgren. 1973. On the metabolic conversion of human plasma very low density lipoprotein to low density lipoprotein. Biochim. Biophys. Acta. 326: 361-377.

48. Berman, M., M. Hall, III., R. I. Levy, S. Eisenberg, D. W. Bilheimer, R. D. Phair, and R. H. Goebel. 1978. Metabolism of apo B and apo C lipoproteins in man: kinetic studies in normal and hyperlipoproteinemic subjects. J. Lipid Res. 19: 38-56.

49. Janus, E. D., A. Nicoll, R. Wootton, P. R. Turner, P. J. Magill, and B. Lewis. 1980. Quantitative studies of very low density lipoprotein: conversion to low density lipoprotein in normal controls and primary hyperlipidaemic states and the role of direct secretion of low density lipoprotein in heterozygous familial hypercholesterolaemia. Eur. J. Clin. Invest. 10: 149-159.

50. Nestel, P. J., T. Billington, and B. Smith. 1981. Low density and high density lipoprotein kinetics and sterol balance in vegetarians. Metab. Clin. Exp. 30: 941-945

51. Kovanen, P. T., D. W. Bilheimer, J. L. Goldstein, J. J. Jaramillo, and M. S. Brown. 1981. Regulatory role for hepatic low density lipoprotein receptors in vivo in the dog. Proc. Natl. Acad. Sci. U. S. A. 78: 1194-1198

52. Slater, H. R., C. J. Packard, S. Bicker, and J. Shepherd. 1980. Effects of cholestyramine on receptor-mediated plasma clearance and tissue uptake of human low density lipoproteins in the rabbit. J. Biol. Chem. 255: 1021010213.

53. Shepherd, J., C. J. Packard, S. Bicker, T. D. V. Lawrie, and H. G. Morgan. 1980. Cholestyramine promotes receptor-mediated low-density-lipoprotein catabolism. $N$. Engl. J. Med. 302: 1219-1222.

54. Sniderman, A., S. Shapiro, D. Marpole, B. Skinner, B. Teng, and P. O. Kwiterovich, Jr. 1980. Association of coronary atherosclerosis with hyperapobetalipoproteinemia [Increased protein but normal cholesterol levels in human plasma low density $(\beta)$ lipoproteins]. Proc. Natl. Acad. Sci. U. S. A. 77: 604-608.

55. Quintao, E., S. M. Grundy, and E. H. Ahrens, Jr. 1971. Effects of dietary cholesterol on the regulation of total body cholesterol in man. J. Lipid Res. 12: 233-247.

56. Grundy, S. M., E. H. Ahrens, Jr., G. Salen, P. H. Schreibman, and P. J. Nestel. 1972. Mechanism of action of clofibrate on cholesterol metabolism in patients with hyperlipidemia. J. Lipid Res. 13: 531-551. 